\title{
BMJ Open Risk of postneonatal mortality, hospitalisation and suboptimal breast feeding practices in low birthweight infants from rural Haryana, India: findings from a secondary data analysis
}

\author{
Ravi Prakash Upadhyay, ${ }^{1}$ Jose Carlos Martines, ${ }^{2}$ Sunita Taneja, ${ }^{1}$ \\ Sarmila Mazumder, ${ }^{1}$ Rajiv Bahl, ${ }^{3}$ Nita Bhandari, ${ }^{1}$ Suresh Dalpath, ${ }^{4}$ \\ Maharaj Kishan Bhan ${ }^{5,6}$
}

To cite: Upadhyay RP, Martines JC, Taneja S, et al. Risk of postneonatal mortality, hospitalisation and suboptimal breast feeding practices in low birthweight infants from rural Haryana, India: findings from a secondary data analysis. BMJ Open 2018;8:e20384. doi:10.1136/ bmjopen-2017-020384

- Prepublication history and additional material for this paper are available online. To view these files, please visit the journal online (http://dx.doi org/10.1136/bmjopen-2017020384).

Received 2 November 2017 Revised 14 April 2018 Accepted 10 May 2018
Check for updates

For numbered affiliations see end of article.

Correspondence to Dr Ravi Prakash Upadhyay; ravi.upadhyay@sas.org.in

\section{ABSTRACT}

Objectives Low birth weight (LBW) is a risk factor for neonatal mortality and morbidity. It is important to examine whether this risk persists beyond neonatal period. The current secondary data analysis aimed to examine association of birth weight with mortality, hospitalisation and breast feeding practices during infancy.

Design Data from a large randomised controlled trial of neonatal vitamin A supplementation (Neovita) trial were used. Log binomial model was applied to assess association between birth weight and mortality, hospitalisation and breast feeding practices.

Setting Rural Haryana, North India.

Participants Newborns recruited in the primary intervention trial that aimed to evaluate the effect of single-dose oral vitamin A supplementation on mortality in the first 6 months of life.

Results We recruited a total of 44984 infants, of which $10658(23.7 \%)$ were born LBW, that is, birth weight less than $2500 \mathrm{~g}$. In the neonatal period, LBW babies had four times higher risk of mortality (relative risk (RR) 3.92; $95 \% \mathrm{Cl} 3.33$ to 4.66 ) compared with normal birthweight babies. In the postneonatal period, the risk was two times higher (RR 1.92; 95\% Cl 1.71 to 2.15); even higher in those with birth weight $<2000 \mathrm{~g}$ (RR 3.38; $95 \% \mathrm{Cl} 2.71$ to 4.12). The risk of hospitalisation in the neonatal period and postneonatal period was (RR 1.86; 95\% Cl 1.64 to 2.11) and (RR $1.13 ; 95 \% \mathrm{Cl} 1.05$ to 1.21 ), respectively. LBWs were at increased risk of breast feeding initiation 24 hours after birth (RR 1.64; 95\% Cl 1.45 to 1.81), no breast feeding at 6 months (RR 1.34; 95\% $\mathrm{Cl} 1.23$ to 1.46) and at 12 months of age (RR $1.24 ; 95 \% \mathrm{Cl} 1.18$ to 1.30 ).

Conclusions LBW babies, especially those with birth weight of $<2000 \mathrm{~g}$, were at increased risk of mortality, hospitalisation and suboptimal breast feeding practices during entire infancy and therefore require additional care beyond the first 28 days of life.

Trial registration number NCT01138449.

\section{INTRODUCTION}

Approximately $15 \%$ of infants in low/ middle-income countries (LMIC) are born
Strengths and limitations of this study

- Robust population-based surveillance system, low loss to follow-up and large sample size.

- Birth weight measured by trained study team, thereby reducing chances of misclassification.

- Findings are generalisable to large parts of Southeast Asia because of similar social, economic and demographic features.

- Main trial did not include babies who either died or were unable to feed in the first 72 hours of birth; $36 \%$ of which were low birth weight. Excluding them in the primary trial may have made the estimates, especially for mortality, more conservative.

- Lack of reliable data on gestational age restricted analysis by prematurity and intrauterine growth retardation.

low birth weight (LBW) (ie, birth weight $<2500$ g). ${ }^{1}$ In 2010, in LMICs, an estimated 18 million infants were born with LBW, of which around 7.5 million babies $(41 \%)$ were born in India alone. ${ }^{1}$ LBW infants face high risk of poor health outcomes such as growth retardation, developmental delay and death. ${ }^{2-5}$ Recent studies on mortality risk by gestational age in LMICs document high risk of neonatal as well as postneonatal mortality in preterms and small for gestational age infants. ${ }^{6} 7$ Existing programmes for infant care, globally as well as in India, are heavily investing in improving facility-based care for small and sick infants alongside efforts to increase institutional deliveries so that quality care, without delay, could be provided to 'at-risk' newborns. In India, with the introduction of government schemes such as Janani Suraksha Yojana (JSY) and Janani Shishu Suraksha Karyakram (JSSK), a substantial increase in institutional 
deliveries has occurred. ${ }^{8}{ }^{9}$ According to the recent National Family Health Survey-4, the institutional delivery rate for India is $79 \% .{ }^{10} \mathrm{JSY}$, a conditional cash transfer scheme, was introduced in the year 2005 , with a strategy to link cash assistance to institutional delivery. ${ }^{89}$ Due to JSY, institutional deliveries across the country increased but with a few limitations such as high out-of-pocket expenditure by families especially for purchase of the drugs and transport. In the view of these limitations, Government of India introduced JSSK scheme in June 2011. ${ }^{9}$ Under this scheme-birth of the baby through normal vaginal delivery, caesarean section, drugs and consumables, diagnostics and transport between home and health facility are provided free of cost. ${ }^{9}$

Newborn care facilities have been established at various levels of Indian public health system. These include newborn care corners to provide immediate care after childbirth; newborn stabilisation units at community health centres/first referral units for management of selected conditions and to stabilise sick newborns before referral to higher centres; and Special Newborn Care Units at district/subdistrict hospitals to care for sick newborns. ${ }^{11}$ Postdischarge from the birth facility, all newborns are to be visited by a community health worker; a total of six visits within 42 days of age. These visits aim to promote essential newborn care practices, early detection and special care of preterm and low birthweight infants, early identification of illness and provision of appropriate care and referral. ${ }^{12}$ Post- 42 days of age, interaction of infants with the health system is largely dependent on family action, centred around taking the baby for immunisation and care seeking for illness. A sustained support to promote survival and growth at household level especially to those born with LBW is infrequent, weak and fragmented.

It is important to examine whether child health programmes should provide special and more intense surveillance and support beyond 42 days for those with LBW. Further, should the additional surveillance and support be directed to a subpopulation of LBWs or should it be provided to all LBWs? The evidence that would compel additional follow-up and support should be based on the additional risk of mortality, morbidity, stunting and cognitive deficits in the LBWs. We believe contemporary data on the outcome of LBW infants for the neonatal and postneonatal periods are required to determine the extent to which home care programme needs to be stretched. Home care programmes cost resources and policymakers require local evidence from recent data on adverse outcomes including mortality rates.

With the aim of adding to the evidence base, we performed a secondary data analysis utilising the data from an individually randomised, double-masked, placebo controlled trial. The primary trial aimed at assessing the efficacy of neonatal oral supplementation with vitamin A within 72 hours of birth in reducing mortality within 6 months of infant age. ${ }^{13}$ The study found no effect of intervention on mortality between supplementation and 6 months of age. The underlying hypothesis of the current secondary data analysis was that LBW infants would be at a higher risk of mortality, hospitalisation and suboptimal breast feeding practices during entire infancy, compared with those with normal birth weight (ie, birth weight $\geq 2500 \mathrm{~g}$ ). The primary objective of the analysis was to examine the relationship between birth weight and mortality in infants born in rural Haryana, India. As a secondary objective, association of birth weight with hospitalisation and breast feeding practices was examined. This information may be helpful to improve the design and intensity of efforts for additional care directed towards low birthweight infants in the postneonatal period.

\section{METHODS \\ Study design and setting}

We conducted secondary analysis on data from the Neovita trial, a large individually randomised, doublemasked, placebo controlled trial of neonatal vitamin A supplementation. ${ }^{1314}$ This study was conducted from June 2010 until July 2012, in Faridabad and Palwal districts in the state of Haryana, North India. The primary aim of the trial was to evaluate the effect of single-dose vitamin A supplementation, given within 72 hours of birth, on mortality in the first 6 months of life. The trial procedures and details of study area have been described in detail elsewhere. ${ }^{13} 14$

\section{Ethical clearance}

The primary trial (Neovita) was funded by WHO through a grant from Bill and Melinda Gates Foundation. The trial is registered with ClinicalTrials.gov, number NCT01138449. All the concerned investigators of the primary trial gave permission to use the data for this secondary analysis.

\section{Enrolment and data collection}

The primary trial aimed to assess the efficacy of neonatal oral vitamin A supplementation on mortality within 6 months of age. Only those infants were included in the trial who were identified within 72 hours of birth so that the intervention could be given as close to birth as possible. Pregnant women were identified through periodic household surveillance. For each live birth identified, the study team visited the family, explained the trial and screened the infant against predefined eligibility criteria (infant aged $\leq 72$ hours at screening who could suck or feed and whose family members intended to stay in the study area for at least 6 months). Written consent was obtained from at least one parent, that is, mother or father of the eligible infant. The enrolled infant was weighed by the study team members who were trained and standardised for birth weight measurement. Restandardisation exercises were done every 6 months. An independent team of study supervisors did random spot checks of all workers once a month and monitored quality of performance. 
At enrolment, information was collected on household characteristics (caste, religion and socioeconomic variables to ascertain wealth quintile), infant characteristics (birth weight and sex), birth-related characteristics (place of delivery, multiple births, parity) and maternal characteristics (age, education and occupation). Infants were visited on the first and third days to document postsupplementation adverse events and to obtain information on the time of breast feeding initiation in hours after birth (if not already initiated at the enrolment visit) and colostrum intake.

Each enrolled infant was followed up until 12 months of age. Infants were contacted when aged 29 days and at 3,6 and 12 months and at each visit, information was collected or ascertained on feeding practices, hospitalisation since last visit and vital status. The study team member asked about what the infant was fed in the previous 24 hours from the time of visit, including breast milk, plain water, animal milk, other fluids, medicines and solid food. A hospitalisation was defined as either an inpatient admission (where an infant received an inpatient slip with a registration number and allotted a bed) or a stay of $\geq 6$ hours' duration in the hospital including the emergency services, diarrhoea management room or any paediatric wards of the institution.

Information on hospitalisation was collected through hospital records and documents and in instances where a hospital record could not be found, information provided by the mother was considered. At the first follow-up visit at 29 days, data on hospitalisation were gathered since the infant was enrolled in the study. For subsequent follow-up visits, information on hospitalisation was collected since the last follow-up visit.

\section{Operational definitions used}

Delayed initiation of breast feeding - was defined as infant being initiated on breast feeding after an hour of birth ( $>1$ hour after birth). ${ }^{15}$ This operational definition was same for infants born through normal vaginal and caesarean delivery. An additional outcome was also considered-'breast feeding after 24hours of birth', based on the findings of a recent review that indicated increased risk of mortality in infants who were initiated breast feeding 24 hours after birth compared with those initiated $\leq 1$ hour after birth. ${ }^{16}$

Exclusive breast feeding — defined as infant being given no other food or drink, not even water, except breast milk (including milk expressed or from a wet nurse), with the exception of infant receiving oral rehydration salt, drops and syrups (vitamins, minerals and medicines). ${ }^{15}$

\section{Outcomes for the secondary analysis}

The primary outcome in our analysis was the association between birth weight and mortality during infancy. Secondary outcomes were association of birth weight with hospitalisation and breast feeding practices, that is, delayed initiation of breast feeding, breast feeding initiation after 24 hours of birth, non-exclusive breast feeding at 1 and 3 months of age, and early termination of breast feeding, that is, no breast feeding at 6 and 12 months of age.

\section{Data analysis}

For the analysis, infants with information on birth weight, vital status, episodes of hospitalisation, breast feeding practices and data on covariates were included. Data analysis was performed using STATA V.11 (StataCorp, College Station, TX). The distribution of the data was examined. Proportions were calculated for categorical variables.

For analysis of mortality rates in the neonatal period, all babies enrolled in the trial were considered. For analysis of mortality between 29 and 90 days of age, 29 and 180 days of age, and 29 and 365 days of age, only infants who were alive at 29 days of age were included in the analysis. Similarly, for analysis of hospitalisation in the neonatal period, all infants enrolled in the trial for which data on hospitalisation were available were considered. For analysis of hospitalisation from 29 to 90 days of age, 29 to 180 days of age and 29 to 365 days of age, only infants who were alive at 29 days and had data on hospitalisation within the specified time period were included in the analysis.

For delayed initiation of breast feeding and breast feeding after 24 hours of birth, infants were included in the analysis only if breast feeding was initiated at any time after birth. For non-exclusive breast feeding at 1 and 3 months, only infants alive at 1 month and 3 months of age, respectively, for whom breast feeding data were available, were included in the analysis. Similarly, for no breast feeding at 6 and 12 months of age, only infants who were alive at 6 and 12 months and information was available on their breast feeding status were included in the analysis. Infants in whom breast feeding was reported to be stopped at the time of visits at 6 and 12 months of age, irrespective of their prior breast feeding status, were included under 'no breast feeding' category.

Log binomial model was used to assess the relationship between birth weight and mortality, hospitalisation and breast feeding practices. For small number of events, as it was for most of the outcomes assessed in this study, relative risk (RR) and OR are usually comparable in magnitude and either of the two could be used. We used RR to express effect sizes as infants were prospectively followed up since enrolment into the study until 12 months of age. Birth weight was the exposure of interest and was categorised into $\geq 2500,2000-2499$ and $<2000$ g. Birth weight category of $<1500 \mathrm{~g}$ was not considered because of a very small proportion of infants in this weight category $(<1 \%)$. Adjustment was done for other covariates that were significant on univariate analysis at a $p$ value of $<0.20 .{ }^{17}{ }^{18}$ Covariates considered were: infant sex, multiple births, maternal age, maternal education, parity, place of delivery, type of delivery, religion, caste, wealth quintile and administration of single dose of vitamin A (intervention in the primary trial). Reliable gestational age data based on ultrasound could not be obtained, 
and therefore analysis based on prematurity and intrauterine growth retardation could not be conducted. Assessment for effect modification (ie, potential interaction) between birth weight and all covariates was done using an interaction term in the model. Likelihood ratio test was used to compare models with or without the interaction term. Post hoc power calculation was also done for the outcomes related to mortality, hospitalisation and breast feeding practices at all the age ranges considered for the analysis. Population attributable risks (PAR) were calculated against each birth weight category for each of the three outcomes, that is, mortality, hospitalisation and breast feeding practices across the different age ranges. PARs were calculated using the following formula: $\mathrm{P}_{\mathrm{pop}} \times(\mathrm{RR}-1) /\left[\mathrm{P}_{\mathrm{pop}} \times(\mathrm{RR}-1)+1\right]$; where $\mathrm{P}_{\mathrm{pop}}=$ proportion of exposed subjects in the study population and $\mathrm{RR}=$ risk ratio. ${ }^{19}{ }^{20}$ Kaplan-Meier survival curves for mortality were generated, by birth weight categories, for different time periods during infancy, that is, enrolment to 28 days of age, enrolment to 3 months of age, enrolment to 6 months of age and enrolment to 12 months of age.

\section{Patient and public involvement}

The current study involves secondary data analysis and therefore patients and/or public were not directly involved in the conduct of the study.

\section{RESULTS}

\section{Characteristics of the study population}

Figure 1 shows the overall flow of study participants in the primary trial. A total of 44984 infants were recruited within 72 hours of birth, of which $65 \%$ were enrolled within 24 hours of birth. The characteristics of the population are presented in table 1 . Out of the enrolled infants, $10658(23.7 \%)$ weighed $<2500 \mathrm{~g}$. The mean birth weight (SD) was 2732.9 (420.1) g. Mean (SD) age of mothers was 23.9 (4.1) years. Nearly half of the infants were born at home $(43.3 \%)$; a third of the mothers were primiparous $(32.7 \%)$ and around half of the infants were male $(52.1 \%)$.

\section{Association of birth weight with mortality during infancy}

Analysis on association of birth weight with mortality outcome at all age ranges considered in the analysis, that is, enrolment to 28 days, 29-90 days, 29-180 days and 29-365 days, had a power of $100 \%$ at an alpha of 0.05 . Table 2 shows the association between birth weight and mortality during the first year of life. After adjustment for covariates, being born with LBW, especially with a birth weight of less than $2000 \mathrm{~g}$, was associated with higher risk of mortality compared with normal birthweight infants during the whole infancy. Online supplementary table 1 shows the findings of univariate analysis of covariates with mortality outcome during the neonatal and postneonatal periods. In the neonatal period, those with birth weight between 2000 and $2499 \mathrm{~g}$ had around 2.5-fold higher risk of death (RR 2.56; 95\% CI 2.13 to 3.12) while those with $<2000 \mathrm{~g}$ had 16 times higher risk (RR 15.64; 95\% CI 12.90 to 19.44). After the neonatal period, this increased risk of death in LBWs was observed between 29 and 90 days of age (RR 2.14; 95\% CI 1.74 to 2.58), 29 and 180 days of age (RR 2.08; 95\% CI 1.77 to 2.36) and 29 and 365 days of age (RR 1.92; $95 \%$ CI 1.71 to 2.15 ). In context of mortality, the PAR for LBW was as high as $41 \%$ in the neonatal period and $17.6 \%$ for the postneonatal period until end of infancy. No statistically significant interaction was found between birth weight and the covariates included in the model for both neonatal and postneonatal mortality. The interaction was specifically assessed for infant sex and was non-significant ( $p$ values of 0.147 and 0.284 for neonatal and postneonatal mortality, respectively). Figure 2 presents the Kaplan-Meier survival curves for mortality as an outcome, by birth weight categories, during different time periods of infancy. It shows that throughout the infancy, the probability of survival for those with birth weight $<2000 \mathrm{~g}$ was comparatively lower than those with normal birth weight, that is, $\geq 2500 \mathrm{~g}$.

Association of birth weight with hospitalisation during infancy For risk of hospitalisation in the neonatal period (ie, enrolment to 28 days), the comparison between normal and low birthweight infants had a power of $100 \%$. The power was lower for analysis of risk of hospitalisation between 29 and 90 days of age $(38.8 \%)$, between 29 and 180 days of age $(41.3 \%)$ and between 29 and 365 days of age (46.6\%). Online supplementary table 2 shows the findings of univariate analysis of covariates with hospitalisation as an outcome, during the neonatal and postneonatal periods. In the neonatal period, low birthweight infants were at an increased risk for hospitalisation (RR 1.86; 95\% CI 1.64 to 2.11) compared with normal birthweight infants after adjustment for all potential covariates. This increased risk was observed in infants with birth weight between 2000 and $2499 \mathrm{~g}$ (RR 1.73; 95\% CI 1.52 to 1.98 ) and was even higher among those $<2000 \mathrm{~g}$ (RR 3.13; 95\% CI 2.45 to 3.99) (table 3). For the rest of infancy, although LBW infants remained at an increased risk of hospitalisation, this risk was largely driven by infants $<2000 \mathrm{~g}$. Overall, the RR of hospitalisation between 29 and 365 days of age was 1.13 (95\% CI 1.05 to 1.21 ) in LBW infants and for those with birth weight $<2000 \mathrm{~g}$, it was 1.74 (95\% CI 1.46 to 2.06). The PAR for hospitalisation in LBWs was around $17 \%$ in the neonatal period and reduced to only $3 \%$ in postneonatal period until 365 days of age (table 3). No statistically significant interaction was found between birth weight and the covariates included in the model for hospitalisation. For infant sex, the interaction effect was non-significant ( $p$ values of 0.988 and 0.621 for hospitalisation in the neonatal and postneonatal periods, respectively).

\section{Association of birth weight with breast feeding practices}

Overall, close to two-thirds of LBW babies (65.9\%) had delayed initiation of breast feeding, that is, after 1 


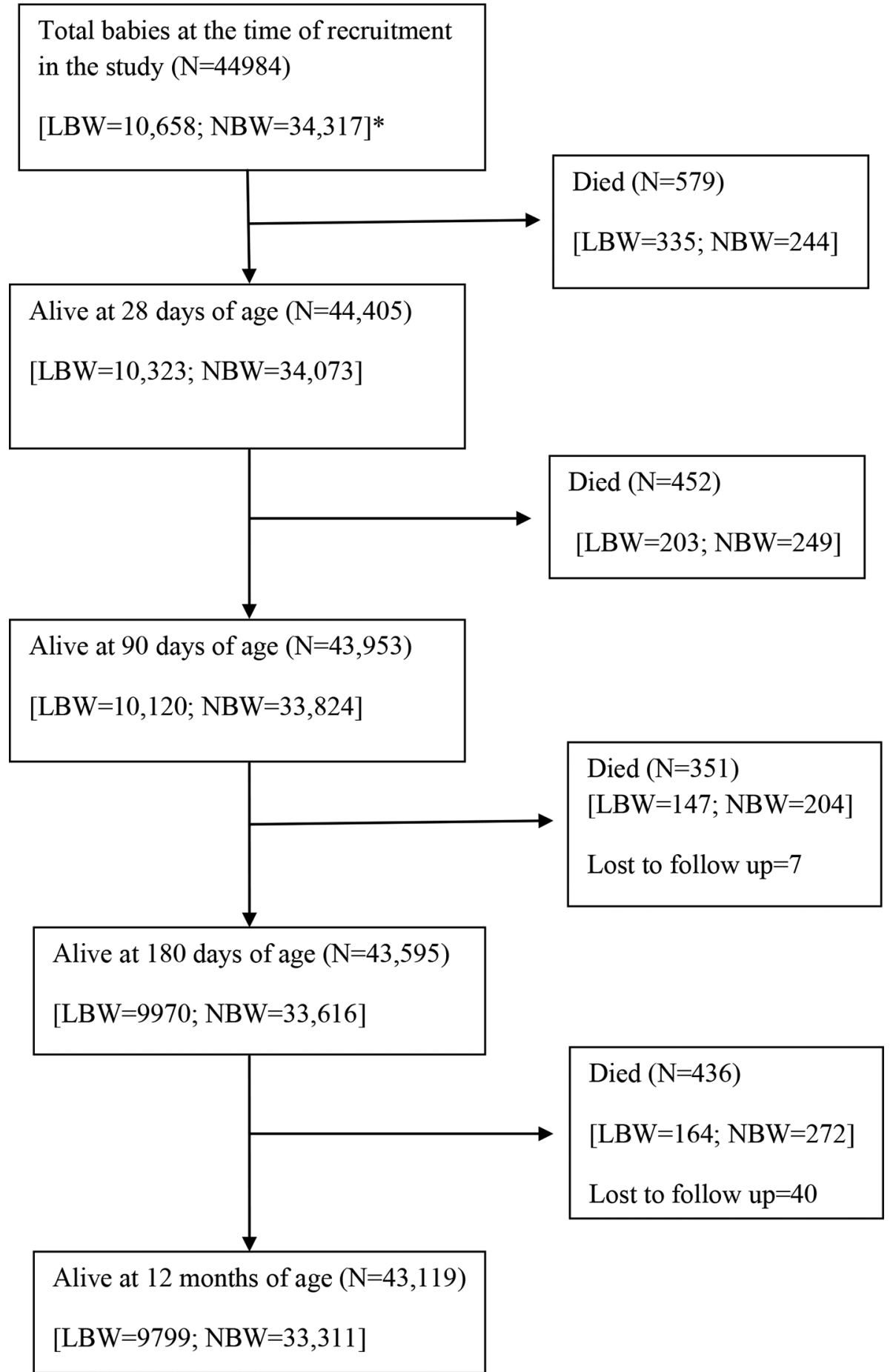

Figure 1 Overall flow of infants recruited in the primary trial. *Nine infants had data missing on birth weight. LBW, low birth weight; NBW, normal birth weight.

hour of birth. Majority of LBW babies $(63.7 \%)$ were not exclusively breast fed by 1 and even more $(78.2 \%)$ by 3 months of age (table 4). At 6 and 12 months, around $8 \%$ and $18 \%$ of LBW infants were not at all breast fed, respectively. Suboptimal breast feeding practices were significantly associated with LBW, especially with a birth weight of $<2000 \mathrm{~g}$, after adjustment for all possible confounding variables (table 4). Analysis on comparison of risk for delayed initiation of breast feeding ( $>1$ hour after birth), breast feeding initiation after 24 hours of birth, non-exclusive breast feeding at 1 month of age and no breast milk feeding at 6 and 12 months of age among normal and low birthweight infants had a power of $>90 \%$; however, the power was $54.6 \%$ for risk of non-exclusive breast feeding at 3 months of age.

Online supplementary table 2 shows the findings of the univariate analysis of covariates with breast feeding outcomes. Compared with infants with normal birth weight, those with birth weight of $<2500 \mathrm{~g}$ had a slightly higher risk of initiating breast feeding after 1 hour of 
Table 1 Baseline characteristics of infants randomised in the primary trial $(n=44984)$

\begin{tabular}{|c|c|}
\hline Variables & n (\%) \\
\hline \multicolumn{2}{|l|}{ Household characteristics } \\
\hline \multicolumn{2}{|l|}{ Religion } \\
\hline Hindu & $34573(76.9)$ \\
\hline Muslim & $9906(22.0)$ \\
\hline Others* & $505(1.1)$ \\
\hline \multicolumn{2}{|l|}{ Caste† } \\
\hline General & $12041(26.8)$ \\
\hline Other backward class (OBC) & $21892(48.7)$ \\
\hline Scheduled caste/tribe (SC/ST) & $11051(24.5)$ \\
\hline \multicolumn{2}{|l|}{ Maternal characteristics } \\
\hline \multicolumn{2}{|l|}{ Mother's age (years) } \\
\hline$<20$ & $3563(8.0)$ \\
\hline $20-30$ & $38747(86.1)$ \\
\hline$>30$ & $2674(5.9)$ \\
\hline \multicolumn{2}{|c|}{ Mother's education (years of schooling) } \\
\hline Illiterate (0) & $18814(41.8)$ \\
\hline 1 to $\leq 9$ & $16667(37.1)$ \\
\hline 10 to $<12$ & $4383(9.7)$ \\
\hline$\geq 12$ & $5120(11.4)$ \\
\hline \multicolumn{2}{|l|}{ Mother's working status } \\
\hline Work outside home & $1142(2.5)$ \\
\hline Homemaker & $43842(97.5)$ \\
\hline \multicolumn{2}{|l|}{ Birth-related characteristics } \\
\hline \multicolumn{2}{|l|}{ Place of delivery $\ddagger$} \\
\hline Home & $19478(43.3)$ \\
\hline Government facility & $14136(31.4)$ \\
\hline Private facility & $11326(25.2)$ \\
\hline \multicolumn{2}{|l|}{ Type of delivery } \\
\hline Normal & $42210(93.8)$ \\
\hline Caesarean & $2592(5.8)$ \\
\hline Assisted & $182(0.4)$ \\
\hline Singleton & $44413(98.7)$ \\
\hline Multiple & $571(1.3)$ \\
\hline \multicolumn{2}{|l|}{ Parity } \\
\hline Multiparity & $30257(67.3)$ \\
\hline Primiparity & $14727(32.7)$ \\
\hline \multicolumn{2}{|l|}{ Infant characteristics } \\
\hline \multicolumn{2}{|l|}{ Sex of the baby } \\
\hline Male & $23418(52.1)$ \\
\hline Female & $21566(47.9)$ \\
\hline \multicolumn{2}{|l|}{ Birth weight $(\mathrm{g}) \S$} \\
\hline$\geq 2500$ & $34317(76.3)$ \\
\hline $2000-2499$ & $9403(20.9)$ \\
\hline$<2000$ & $1255(2.8)$ \\
\hline
\end{tabular}

${ }^{*}$ Others-Christian/Sikh/Jain/Parsi/Zoroastrian/Buddhist/neo-Buddhist. †General-groups that do not qualify for any of the positive discrimination schemes by Government of India (GOI), OBC-term used by the Government of India to classify castes which are socially and educationally disadvantaged, SC/ST - official designations given to groups of historically disadvantaged indigenous people in India. fRemaining 44 births took place on way to health facility. $\S N i n e$ infants had data missing on birth weight. birth (RR $1.03 ; 95 \%$ CI 1.01 to 1.06 ) and a substantially higher risk of initiating after 24 hours of birth (RR 1.64; $95 \%$ CI 1.45 to 1.81 ).

A higher risk of non-exclusive breast feeding at 1 (RR 1.07; 95\% CI 1.02 to 1.15 ) and 3 (RR 1.08; 95\% CI 1.03 to 1.14) months was observed only in infants with birth weight of $<2000 \mathrm{~g}$. LBW infants were at a much higher risk of not being breast fed at all, compared with normal birthweight infants, at 6 months (RR 1.34; $95 \%$ CI 1.23 to 1.46) and 12 months (RR 1.24; 95\% CI 1.18 to 1.30 ) of age. The risk was higher in infants with birth weight of less than $2000 \mathrm{~g}$, that is, (RR 1.49; 95\% CI 1.20 to 1.86 ) at 6 months and (RR 1.36; 95\% CI 1.18 to 1.56 ) at 12 months of age. The PAR for suboptimal breast feeding practices in LBW infants was around $13.3 \%$ for initiation of breast feeding beyond 24 hours of birth; $7.2 \%$ for no breast feeding at 6 months and $5.1 \%$ for no breast feeding at 12 months of age. No statistically significant interaction of the covariates with birth weight was observed for any of the outcomes considered.

\section{DISCUSSION}

This secondary data analysis showed that in low birthweight infants, compared with those with normal birth weight, mortality in the neonatal as well as in the postneonatal period until 1 year of age was substantially higher. The PAR for mortality in low birthweight infants was highest in the neonatal period and declined at 12 months of age. The risk for hospitalisation, reflecting severe morbidity, in both <2000 and 2000-2499 g babies was higher compared with normal birthweight infants in the neonatal period; however, in postneonatal period, the excess risk was seen only in $<2000 \mathrm{~g}$ infants. The risk of delayed initiation of breast feeding and early termination of breast feeding at 6 and 12 months of age was higher in the low birthweight group and the strength of association was substantially greater for those below $2000 \mathrm{~g}$. The PAR for delayed initiation of breast feeding beyond 24 hours of birth was around $13 \%$. An additional $7 \%$ and $5 \%$ of 'continued breast feeding' rates at 6 and 12 months, respectively, could be potentially achieved by focusing on promoting breast feeding practices in low birthweight infants, beyond the neonatal period. Achieving even this much magnitude of benefit in appropriate breast feeding practices is crucial as early initiation of breast feeding and continued breast feeding during the first year of life and particularly in early infancy has been shown to be associated with improved survival and lesser morbidity. ${ }^{21} 22$

The findings of the study corroborate well with the previously published literature from LMICs. Katz et al in their pooled analysis, utilising data from 20 cohorts from Asia, Africa and Latin America, documented the risk of postneonatal mortality in preterm (RR 2.50; 95\% CI 1.48 to 4.22 ) and small for gestational age (RR 1.90; 95\% CI 1.32 to 2.73 ) infants. Their findings are similar to what we have observed in the current analysis. ${ }^{7}$ A cohort study of LBW infants and their health outcomes in the first 
Table 2 Association of mortality rates in the first year of life by birth weight in infants from rural Haryana, North India

\begin{tabular}{lllll}
$\begin{array}{l}\text { Number of deaths } \\
\text { (rate per } 1000 \text { live } \\
\text { births }\end{array}$ & $\begin{array}{l}\text { Number of } \\
\text { infants } \dagger\end{array}$ & Univariate & & Multivariate \\
\cline { 2 - 3 }$(95 \% \mathrm{Cl})$ & RR $(95 \% \mathrm{Cl})$ & PAR (\%)
\end{tabular}

Neonatal mortality (from enrolment to 28 days)

\begin{tabular}{|c|c|c|c|c|c|}
\hline Total number & - & 44975 & & & \\
\hline \multicolumn{6}{|l|}{ Birth weight (g) } \\
\hline$\geq 2500$ & $244(7.1)$ & $34317(76.3)$ & Ref & Ref & - \\
\hline$<2500$ & 335 (31.4) & $10658(23.7)$ & 4.42 (3.78 to 5.23$)$ & 3.92 (3.33 to 4.66$)$ & 41 \\
\hline 2000-2499 & $181(19.2)$ & $9403(20.9)$ & 2.71 (2.27 to 3.31$)$ & $2.56(2.13 \text { to } 3.12)^{*}$ & 24.6 \\
\hline$<2000$ & $154(122.7)$ & $1255(2.8)$ & 17.28 (14.22 to 20.89$)$ & $15.64(12.90 \text { to } 19.44)^{\star}$ & 29.1 \\
\hline
\end{tabular}

Postneonatal mortality (29-90 days)

Total number $\quad$ - $\quad 44396$

Birth weight (g)

\begin{tabular}{|c|c|c|c|c|c|}
\hline$\geq 2500$ & $249(7.3)$ & $34073(76.8)$ & Ref & Ref & - \\
\hline$<2500$ & 203 (19.7) & $10323(23.2)$ & 2.69 (2.21 to 3.19$)$ & 2.14 (1.74 to 2.58$)$ & 21 \\
\hline 2000-2499 & $126(13.7)$ & $9222(20.7)$ & 1.88 (1.51 to 2.33$)$ & $1.68(1.36 \text { to } 2.08)^{*}$ & 12.3 \\
\hline \multicolumn{6}{|c|}{ Postneonatal mortality (29-180 days) } \\
\hline Total number & - & 44396 & & & \\
\hline$\geq 2500$ & $453(13.3)$ & $34073(76.8)$ & Ref & Ref & - \\
\hline$<2500$ & $350(33.9)$ & $10323(23.2)$ & 2.55 (2.21 to 2.93$)$ & 2.08 (1.77 to 2.36$)$ & 20 \\
\hline 2000-2499 & $249(27.0)$ & $9222(20.7)$ & 2.01 (1.72 to 2.34$)$ & $1.78(1.52 \text { to } 2.09)^{*}$ & 13.9 \\
\hline$<2000$ & $101(91.7)$ & $1101(2.5)$ & 6.89 (5.47 to 8.36$)$ & $4.24(3.28 \text { to } 5.37)^{\star}$ & 7.5 \\
\hline
\end{tabular}

Postneonatal mortality (29-365 days)

\begin{tabular}{llccrc}
$\begin{array}{l}\text { Total number } \\
\text { Birth weight }(\mathrm{g})\end{array}$ & - & \multicolumn{5}{c}{44396} \\
$\geq 2500$ & $725(21.3)$ & $34073(76.8)$ & Ref & Ref & - \\
$<2500$ & $514(49.8)$ & $10323(23.2)$ & $2.33(2.07$ to 2.58$)$ & $1.92(1.71$ to 2.15$)$ & 17.6 \\
$2000-2499$ & $392(42.5)$ & $9222(20.7)$ & $1.99(1.76$ to 2.24$)$ & $1.76(1.54$ to 1.99$)$ & 13.6 \\
$<2000$ & $122(110.8)$ & $1101(2.5)$ & $5.20(4.34$ to 6.16$)$ & $3.38(2.71$ to 4.12$)$ & 5.6 \\
\hline
\end{tabular}

*Statistical significance at $p<0.05$.

†Nine infants had data missing on birth weight.

$\ddagger$ Adjusted for place of delivery, type of delivery, multiple births, mother’s education, mother’s age, religion, caste, wealth quintiles, parity, infant sex, administration of vitamin A (intervention in the primary trial).

PAR, population attributable risk; RR, relative risk.

year of life from rural Ghana also found increased risk of mortality in LBWs in the postneonatal period compared with normal birthweight infants. ${ }^{23}$ Also, the risk of illness in LBW infants, compared with normal birthweight infants, declined in the postneonatal period, similar to what the current analysis documents. ${ }^{23}$

In the same data set, we have also observed that LBW infants were at an increased risk of delay in receiving vaccination and being incompletely immunised by the end of infancy. Less than one-third (29.7\%) of LBW infants were fully immunised by 1 year of age and proportion with delayed vaccination for DPT1 and DPT3 was $52 \%$ and $81 \%$, respectively. ${ }^{24}$ In India, a little more than one-fourth of the babies are born with LBW. ${ }^{25}$ The proportion of LBW varies by states and ranges from $22 \%$ to $36 \% .{ }^{26}$ Provision of quality care of small and sick babies is a priority issue in order to improve survival, growth and thrive of this vulnerable subset of infants. Health facilities have provision for care of small and sick infants and the home visitation programme until 42 days of age aims to improve neonatal survival and reduce morbidities, although achieving adequate quality and coverage for these neonatal interventions is a persistent challenge. ${ }^{1112}$

An important issue is to decide whether extended support for infants through health system is needed beyond the neonatal period. An additional question of relevance is whether postneonatal surveillance and support through continued home visitation by healthcare providers 


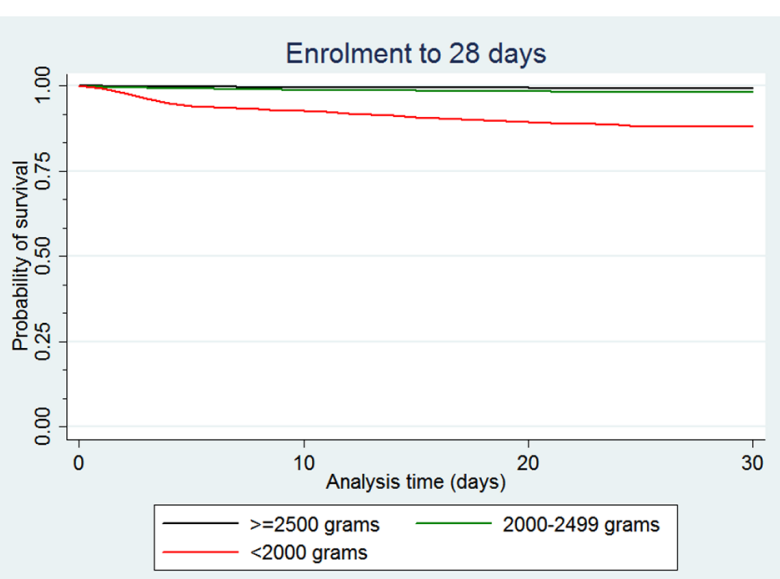

A

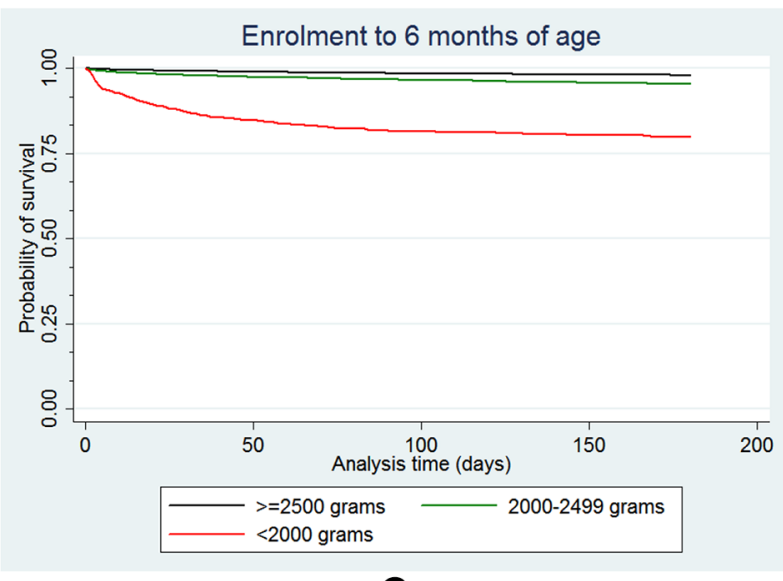

C

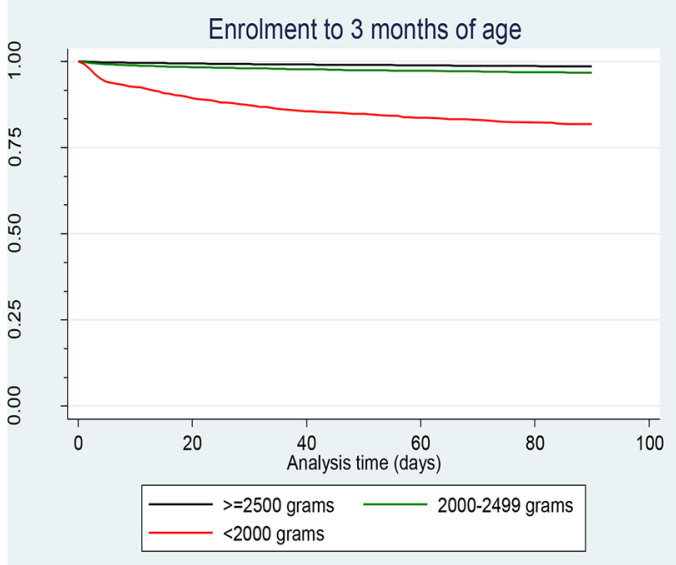

B

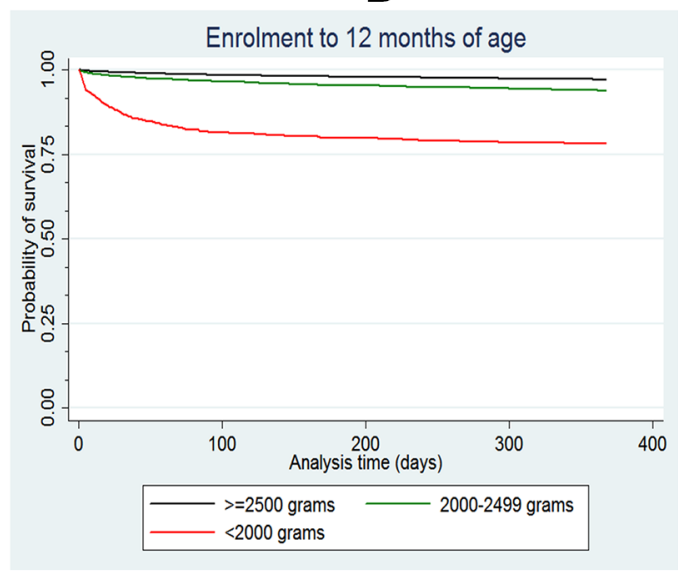

D

Figure 2 (A-D) Kaplan-Meier survival curves for mortality according to categories of birth weight for different time periods during infancy.

should be for all infants or restricted to LBWs. Our data suggest that extended follow-up and support could be for LBW infants and ideally be continued until the end of infancy owing to the high risk of mortality and suboptimal breast feeding practices. However, in resource-constrained settings, from the perspective of mortality reduction, the follow-up could be at least until the first 3 months of life as it would provide maximum reward in terms of proportion of LBWs to be cared for (23.2\%) and the corresponding reduction in mortality (PAR of 21\%). The follow-up for those less than $2000 \mathrm{~g}$ could potentially be extended until the end of infancy as they constitute a small proportion of infants $(2.5 \%)$ and corresponding reduction in mortality would be $5.6 \%$. The extended follow-up would be particularly beneficial in areas where postneonatal mortality is high. Since wasting and stunting are also highly prevalent in India, particularly in those born with LBW, there is a case for extended home-based surveillance and delivery of evidence-based interventions to infants in most parts of the country. ${ }^{27-29}$ The interventions could constitute monthly home visits by community health workers for growth monitoring, counselling caregivers on optimal infant care practices including recognition of illness and prompt care seeking, lactation support, promoting timely immunisation and educating caregivers on appropriate complementary feeding. Such package of interventions might be expected to improve survival, growth and development. In addition, it may lead to lower healthcare costs, particularly out-ofpocket expenses by the family, as in many parts of India care for infant illnesses is commonly sought from private practitioners. $^{3031}$

The current programme during the neonatal period targets all neonates which is appropriate. Our findings suggest the need for increasing the duration of contacts for the LBWs. There should be focus on improving the quality of healthcare provider-family interactions and follow-up action when merited. The current situation where immunisation is the only available contact with LBW, in the postneonatal period, leaves a large proportion of LBW infants vulnerable to premature death or poor growth and development. There is an imminent need for strengthening the existing mechanism of care and support for newborns in the first 42 days of life along with introducing additional care for LBW infants through a dedicated home-based programme throughout the first year of life. Availability of Accredited Social Health Activist who works closer to home gives a unique opportunity to design a programme linking facility to home. ${ }^{32}$

An informed decision whether to focus on all infants must take into account the PAR for other adverse outcomes 
Table 3 Association of hospitalisation for severe morbidity in the first year of life, by birth weight in infants from rural Haryana, North India

\begin{tabular}{|c|c|c|c|c|}
\hline \multirow{2}{*}{$\begin{array}{l}\text { Infants } \\
\text { with } \geq 1 \text { episode(s) } \\
\text { of } \\
\text { hospitalisation (\%) }\end{array}$} & & Univariate & Multivariateł & \\
\hline & Number of infants $\dagger$ & $\begin{array}{l}\text { Unadjusted RR } \\
(95 \% \mathrm{Cl})\end{array}$ & $\begin{array}{l}\text { Adjusted RR } \\
(95 \% \mathrm{Cl})\end{array}$ & PAR (\%) \\
\hline
\end{tabular}

Hospitalisation from enrolment to 28 days

\begin{tabular}{|c|c|c|c|c|c|}
\hline Total number & - & 44481 & & & \\
\hline \multicolumn{6}{|l|}{ Birth weight (g) } \\
\hline$\geq 2500$ & $724(2.13)$ & $34028(76.5)$ & Ref & Ref & - \\
\hline$<2500$ & $383(3.66)$ & $10453(23.5)$ & 1.72 (1.51 to 1.93$)$ & $1.86(1.64 \text { to } 2.11)^{*}$ & 16.8 \\
\hline $2000-2499$ & $311(3.35)$ & $9273(20.8)$ & 1.57 (1.37 to 1.78$)$ & $1.73(1.52 \text { to } 1.98)^{*}$ & 13.2 \\
\hline$<2000$ & $72(6.10)$ & $1180(2.7)$ & 2.89 (2.27 to 3.63$)$ & $3.13(2.45 \text { to } 3.99)^{*}$ & 5.4 \\
\hline
\end{tabular}

Hospitalisation in postneonatal period (29-90 days)

Total number $\quad$ - $\quad 43820$

Birth weight $(\mathrm{g})$

$\begin{array}{lccccc}\geq 2500 & 582(1.73) & 33674(76.8) & \text { Ref } & \text { Ref } & - \\ <2500 & 201(1.98) & 10146(23.2) & 1.15(0.98 \text { to } 1.35) & 1.20(1.02 \text { to } 1.42)^{\star} & 4.4 \\ 2000-2499 & 161(1.78) & 9076(20.7) & 1.03(0.87 \text { to } 1.22) & 1.11(0.93 \text { to } 1.33) & 2.2 \\ <2000 & 40(3.74) & 1070(2.5) & 2.17(1.58 \text { to } 2.97) & 2.11(1.50 \text { to } 2.95)^{\star} & 2.6\end{array}$

Hospitalisation in postneonatal period (29-180 days)

Total number _ _ $\quad 43056$

\begin{tabular}{|c|c|c|c|c|c|}
\hline \multicolumn{6}{|c|}{ Birth weight (g) } \\
\hline$\geq 2500$ & $1444(4.35)$ & 33198 (77.1) & Ref & Ref & - \\
\hline$<2500$ & $469(4.76)$ & 9860 (22.9) & 1.09 (0.98 to 1.21$)$ & $1.15(1.03 \text { to } 1.27)^{\star}$ & 3.3 \\
\hline$<2000$ & $93(9.33)$ & 997 (2.3) & 2.14 (1.76 to 2.62$)$ & $2.08(1.69 \text { to } 2.59)^{\star}$ & 2.4 \\
\hline
\end{tabular}

Hospitalisation in postneonatal period (29-365 days)

Total number _ _ $\quad 42708$

Birth weight (g)

\begin{tabular}{|c|c|c|c|c|c|}
\hline$\geq 2500$ & 3046 (9.23) & 32966 (77.2) & Ref & Ref & - \\
\hline$<2500$ & $960(9.86)$ & $9742(22.8)$ & 1.07 (1.00 to 1.14$)$ & $1.13(1.05 \text { to } 1.21)^{\star}$ & 2.9 \\
\hline 2000-2499 & $803(9.17)$ & $8761(20.5)$ & 0.99 (0.92 to 1.07$)$ & 1.07 (0.98 to 1.15$)$ & 1.4 \\
\hline
\end{tabular}

*Statistical significance at $p<0.05$.

†Denotes the number of infants who were alive at the start point of analysis time frame and had data on hospitalisation during the period under consideration, for example, for analysis of hospitalisation between 1 and 6 months of age, only those infants were included in analysis who were alive at 1 month of age and had data on hospitalisation between 1 and 6 months of age.

$\ddagger$ Adjusted for place of delivery, type of delivery, multiple births, mother's education, mother's age, religion, caste, wealth quintiles, parity, infant sex, administration of vitamin A (intervention in the primary trial).

PAR, population attributable risk; RR, relative risk.

such as stunting. Overall, in areas of high mortality during infancy and high stunting rates, a case can be made for extended home contacts for infants beyond the neonatal period. Whether the cost benefits may be greater and the feasibility increased by focusing such programmes on LBW infants are important aspects to consider.

\section{Strengths and limitations}

The findings of current analysis have adequate generalisability as the social, economic and demographic features of the study setting are fairly representative of large parts of Southeast Asia. The strengths of the study include robust population-based surveillance system, low loss to follow-up and large sample size. Also, for each of the outcomes considered in the analysis, data were available for $>98 \%$ of the infants, reducing the risk of selection bias. All the infants were recruited within 72 hours of birth and their weight was measured by trained study team, thereby reducing chances of misclassification of infants by birth weight. In order to achieve adequate quality of data, the study team members were rigorously trained 
Table 4 Association of breast feeding practices by birth weight in infants from rural Haryana, North India

\begin{tabular}{lllll}
$\begin{array}{l}\text { Number of infants } \\
\text { with outcome of } \\
\text { interest }(\%)\end{array}$ & $\begin{array}{l}\text { Total number of } \\
\text { infants } \dagger\end{array}$ & Univariable & Multivariable & \\
\cline { 2 - 3 } & RR $(95 \% \mathrm{Cl})$ & RR $(95 \% \mathrm{Cl})$ & PAR (\%)
\end{tabular}

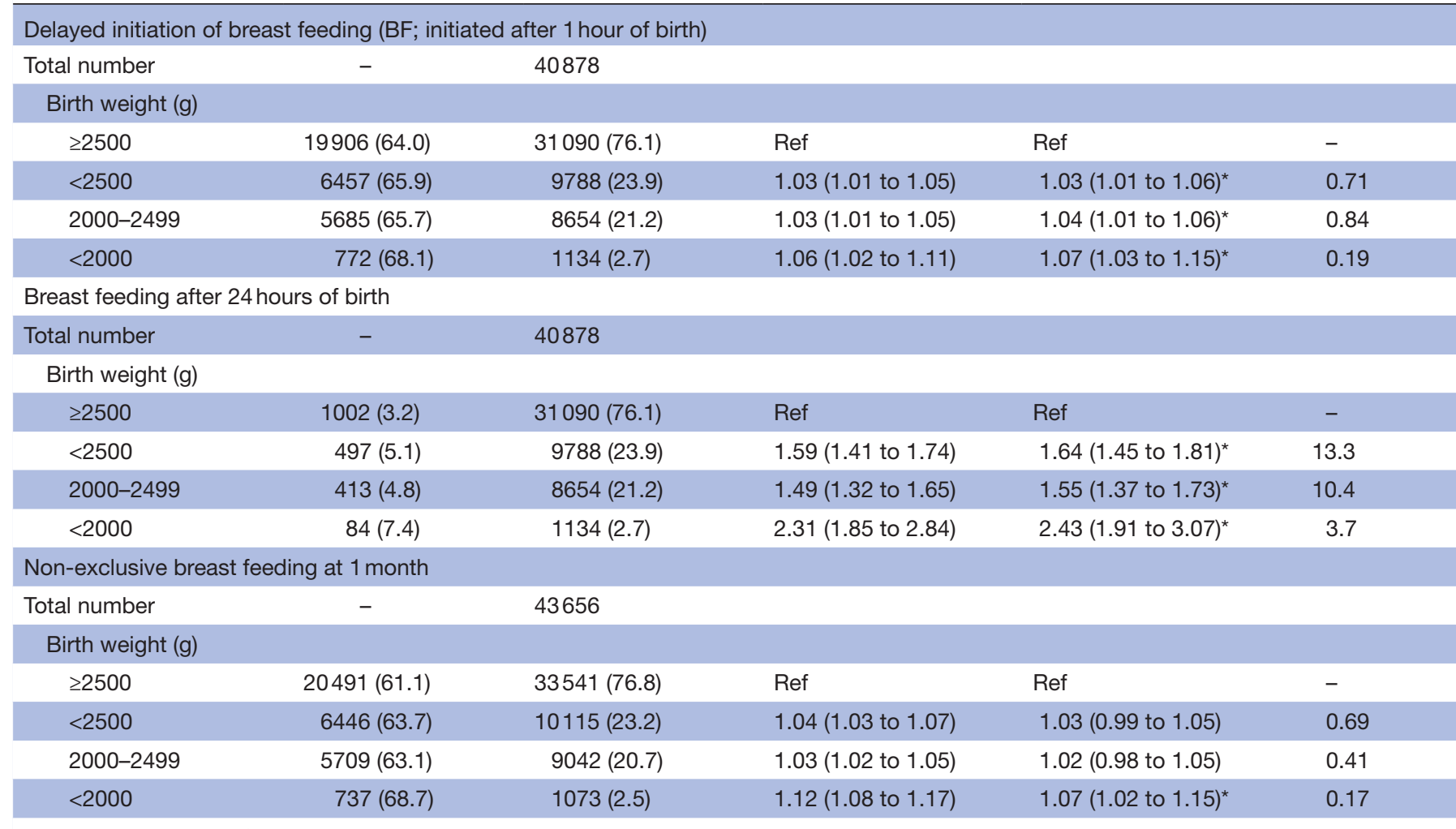

Non-exclusive breast feeding at 3 months

\begin{tabular}{|c|c|c|c|c|c|}
\hline Total number & - & 42628 & & & \\
\hline \multicolumn{6}{|l|}{ Birth weight (g) } \\
\hline$\geq 2500$ & 25401 (77.2) & 32877 (77.1) & Ref & Ref & - \\
\hline 2000-2499 & $6793(77.5)$ & 8759 (20.6) & 1.00 (0.98 to 1.02$)$ & 1.02 (0.97 to 1.06$)$ & 0.41 \\
\hline$<2000$ & $837(84.4)$ & $992(2.3)$ & 1.09 (1.07 to 1.13$)$ & $1.08(1.03 \text { to } 1.14)^{\star}$ & 0.17 \\
\hline
\end{tabular}

No breast feeding at 6 months

Total number

42392

Birth weight $(\mathrm{g})$

\begin{tabular}{|c|c|c|c|c|c|}
\hline$\geq 2500$ & $1936(5.91)$ & 32744 (77.2) & Ref & Ref & - \\
\hline$<2500$ & 778 (8.06) & 9648 (22.8) & 1.36 (1.26 to 1.49$)$ & $1.34(1.23 \text { to } 1.46)^{*}$ & 7.2 \\
\hline 2000-2499 & $682(7.86)$ & $8676(20.5)$ & 1.33 (1.22 to 1.45$)$ & $1.32(1.21 \text { to } 1.45)^{\star}$ & 6.1 \\
\hline$<2000$ & $96(9.87)$ & $972(2.3)$ & 1.67 (1.37 to 2.03 ) & $1.49(1.20 \text { to } 1.86)^{*}$ & 1.1 \\
\hline
\end{tabular}

No breast feeding at 12 months

Total number $\quad-\quad 42492$

Birth weight (g)

\begin{tabular}{lrrlll}
$\geq 2500$ & $4776(14.5)$ & $32883(77.4)$ & Ref & Ref & \multicolumn{1}{l}{} \\
$<2500$ & $1791(18.6)$ & $9609(22.6)$ & $1.28(1.22$ to 1.35$)$ & $1.24(1.18 \text { to } 1.30)^{*}$ & 5.1 \\
$2000-2499$ & $1572(18.2)$ & $8642(20.3)$ & $1.26(1.19$ to 1.32$)$ & $1.23(1.16 \text { to } 1.30)^{*}$ & 4.5 \\
$<2000$ & $219(22.7)$ & $967(2.3)$ & $1.57(1.37$ to 1.78$)$ & $1.36(1.18 \text { to } 1.56)^{*}$ & 0.8 \\
\hline
\end{tabular}

${ }^{*}$ Statistical significance at $p<0.05$.

†Denotes the total number of infants for which desired breast feeding information was available.

$\ddagger$ Adjusted for place of delivery, type of delivery, multiple births, mother's education, mother's age, religion, caste, wealth quintiles, parity,

infant sex, administration of vitamin A (intervention in the primary trial).

PAR, population attributable risk; $R R$, relative risk. 
and underwent periodic interobserver and intraobserver standardisation exercises.

A limitation that must be considered while interpreting the findings is that the main trial did not include babies who were unable to feed in the first 72 hours of birth. This was because the trial aimed at supplementing newborns orally with vitamin A within 72 hours of birth and assess its effect on mortality within 6 months of infant age. To assess whether infants who were not enrolled in the study (ie, those who died before contact for screening, those who could not be enrolled because of serious illness, or those who were admitted in intensive care) were of LBW, attempt was made to obtain birth weights for all infants who were screened but not enrolled. Weights were obtained by study workers at the visit to assess eligibility for screening. Out of the 2793 infants excluded, weights for 2087 were obtained and of these infants, 748 (36\%) were LBW. In such babies, inadequate breast feeding practices, morbidity and mortality would probably have been higher. Excluding them, therefore, may have made our estimates more conservative. The risk of mortality, hospitalisation and suboptimal breast feeding practices might have been more than what we found, had such LBW babies were included in the analysis. There are some other limitations inherent to the secondary data analysis. In the primary trial, reliable data on gestational age were not obtained, making it impossible to assess, in the current analysis, how the outcomes might have been influenced by prematurity. Further, for some of the outcomes such as non-exclusive breast feeding at 3 months of age, hospitalisation between 29 and 90 days of age, 29 and 180 days of age, and 29 and 365 days of age, the power was around $50 \%$.

\section{CONCLUSION}

Low birthweight infants experience high risk of mortality, hospitalisation and suboptimal breast feeding practices even beyond the neonatal period and therefore require continued care and support through health system in order to promote their survival. The current mechanism of home visitation programme in India that focuses on the first 42 days of life may need to be extended to at least cover the first 3 months of infancy and if resources permit, until end of infancy.

\author{
Author affiliations \\ ${ }^{1}$ Centre for Health Research and Development, Society for Applied Studies, New \\ Delhi, India \\ ${ }^{2}$ Centre for Intervention Science in Maternal and Child Health, Centre for \\ International Health, University of Bergen, Bergen, Norway \\ ${ }^{3}$ Department of Maternal, Newborn, Child and Adolescent Health, World Health \\ Organization, Geneva, Switzerland \\ ${ }^{4}$ Department of Health, National Health Mission, Haryana, India \\ ${ }^{5}$ Department of Science and Technology, Indian Institute of Technology (IIT), New \\ Delhi, India \\ ${ }^{6}$ Knowledge Integration and Translational Platform (KnIT), Biotechnology Industry \\ Research Assistance Council (BIRAC), New Delhi, India
}

Acknowledgements The Society for Applied Studies acknowledges the core support provided by the Department of Maternal, Newborn, Child and Adolescent
Health, World Health Organisation, Geneva (WHO Collaborating Centre IND-096) and the Centre for Intervention Science in Maternal and Child Health (RCN Project No 223269), Centre for International Health, University of Bergen (Norway). We also acknowledge the support extended by Clinical Development Services Agency (an autonomous institute established by the Department of Biotechnology, Ministry of Science and Technology, Government of India).

Contributors RPU conceptualsed the study, did the formal analysis and drafted the manuscript. JM conceptualised the study, and helped in analysis and preparation of the manuscript. RB conceptualised the study, helped in the formal analysis and reviewed and revised the manuscript. ST, SM, NB and SD provided overall coordination and supervised data procurement; provided inputs in the analysis, manuscript writing and critically reviewed the manuscript. MKB conceptualised the study, helped in framing the plan of analysis and provided critical feedback throughout the analysis and manuscript preparation. All authors approved the final manuscript as submitted and agree to be accountable for all aspects of the work.

Funding This secondary data analysis was funded by Knowledge Integration and Technology Platform (KnIT), a Grand Challenges Initiative of the Department of Biotechnology and Biotechnology Industry Research Assistance Council (BIRAC) of Government of India and Bill and Melinda Gates Foundation (USA).

Competing interests None declared.

Patient consent Not required.

Ethics approval The trial was approved by the ethics review committes of WHO and Society for Applied Studies, New Delhi. Permission and approvals were taken from the state government of Haryana.

Provenance and peer review Not commissioned; externally peer reviewed.

Data sharing statement № additional data available. Request for data used in the current analysis can be directed to the corresponding author.

Open access This is an open access article distributed in accordance with the Creative Commons Attribution Non Commercial (CC BY-NC 4.0) license, which permits others to distribute, remix, adapt, build upon this work non-commercially, and license their derivative works on different terms, provided the original work is properly cited and the use is non-commercial. See: http://creativecommons.org/ licenses/by-nc/4.0/

(c) Article author(s) (or their employer(s) unless otherwise stated in the text of the article) 2018. All rights reserved. No commercial use is permitted unless otherwise expressly granted.

\section{REFERENCES}

1. Lee $\mathrm{AC}$, Katz J, Blencowe $\mathrm{H}$, et al. National and regional estimates of term and preterm babies born small for gestational age in 138 lowincome and middle-income countries in 2010. Lancet Glob Health 2013;1:e26-36.

2. Murray CJ, Vos T, Lozano R, et al. Disability-adjusted life years (DALYs) for 291 diseases and injuries in 21 regions, 1990-2010: a systematic analysis for the Global Burden of Disease Study 2010. Lancet 2012;380:2197-223.

3. Kelly YJ, Nazroo JY, McMunn A, et al. Birthweight and behavioural problems in children: a modifiable effect? Int $J$ Epidemiol 2001;30:88-94.

4. Hviid A, Melbye M. The impact of birth weight on infectious disease hospitalization in childhood. Am J Epidemiol 2007;165:756-61.

5. Watkins WJ, Kotecha SJ, Kotecha S. All-cause mortality of low birthweight infants in infancy, childhood, and adolescence: population study of England and Wales. PLOS Med 2016;13:e1002018.

6. Black RE, Allen LH, Bhutta ZA, et al. Maternal and child undernutrition: global and regional exposures and health consequences. Lancet 2008;371:243-60.

7. Katz J, Lee AC, Kozuki N, et al. Mortality risk in preterm and small-for-gestational-age infants in low-income and middle-income countries: a pooled country analysis. Lancet 2013;382:417-25.

8. Randive B, Diwan V, De Costa A. India's Conditional Cash Transfer Programme (the JSY) to promote institutional birth: is there an association between institutional birth proportion and maternal mortality? PLoS One 2013;8:e67452.

9. Salve HR, Charlette L, Kankaria A, et al. Improving access to institutional delivery through janani shishu suraksha karyakram: evidence from Rural Haryana, North India. Indian J Community Med 2017;42:73-6. 
10. International Institute for Population Sciences (IIPS) and Macro International. National Family Health Survey (NFHS-4), 2015-16: India Fact Sheet. Mumbai: IIPS. http://rchiips.org/NFHS/pdf/NFHS4/ India.pdf (accessed on 17 Jul 2017).

11. Ministry of Health and Family Welfare, Government of India. Facility based newborn care operational guide. Guidelines for planning and implementation (2011). http://164.100.130.11:8091/rch/FNBC_ Operational_Guideline.pdf (accessed on 21 Jul 2017).

12. Ministry of Health and Family Welfare. Home based newborn care operational guidelines. http://nhm.gov.in/images/pdf/programmes/ child-health/guidelines/Revised_Home_Based_New_Born_Care_ Operational_Guidelines_2014.pdf (accessed on 22 Jul 2017).

13. Mazumder S, Taneja S, Bhatia K, et al. Efficacy of early neonatal supplementation with vitamin A to reduce mortality in infancy in Haryana, India (Neovita): a randomised, double-blind, placebocontrolled trial. Lancet 2015;385:1333-42.

14. Bahl R, Bhandari N, Dube B, et al. Efficacy of early neonatal vitamin A supplementation in reducing mortality during infancy in Ghana, India and Tanzania: study protocol for a randomized controlled trial. Trials 2012;13:22.

15. World Health Organization. Indicators for assessing infant and young child feeding practices: Report of an expert consultation. $2008 \mathrm{http}: / /$ apps.who.int/iris/bitstream/10665/43895/1/9789241596664_eng.pdf (accessed on 23 Jul 2017).

16. Smith ER, Hurt L, Chowdhury R, et al. Delayed breastfeeding initiation and infant survival: A systematic review and meta-analysis. PLoS One 2017;12:e0180722.

17. Lee PH. Should we adjust for a confounder if empirical and theoretical criteria yield contradictory results? A simulation study. Sci Rep 2014;4:6085.

18. Budtz-Jørgensen E, Keiding N, Grandjean P, et al. Confounder selection in environmental epidemiology: assessment of health effects of prenatal mercury exposure. Ann Epidemiol 2007;17:27-35.

19. Rockhill B, Newman B, Weinberg C. Use and misuse of population attributable fractions. Am J Public Health 1998;88:15-19.

20. Canada's University. Attributable Risk and Population Attributable Risk (PAR) Measures. https://www.med.uottawa.ca/sim/data/PAR_e. $\mathrm{htm}$ (accessed on 26 Jul 2017).

21. Kramer MS, Kakuma R. Optimal duration of exclusive breastfeeding. Cochrane Database Syst Rev 2012;8:CD003517.
22. Sankar MJ, Sinha B, Chowdhury R, et al. Optimal breastfeeding practices and infant and child mortality: a systematic review and meta-analysis. Acta Paediatr 2015;104:3-13.

23. O'Leary M, Edmond K, Floyd S, et al. A cohort study of low birth weight and health outcomes in the first year of life, Ghana. Bull World Health Organ 2017;95:574-83.

24. Upadhyay RP, Chowdhury R, Mazumder S, et al. Immunization practices in low birth weight infants from rural Haryana, India: findings from secondary data analysis. J Glob Health 2017;7:020415.

25. Bhilwar M, Upadhyay RP, Yadav K, et al. Estimating the burden of 'weighing less': A systematic review and meta-analysis of low birthweight in India. Natl Med J India 2016;29:73-81.

26. Office of the Registrar General and Census Commissioner, India. Annual Health Survey report: a report on core and vital health indicators (Part1). http://www.censusindia.gov.in/vital_statistics/AHS/ AHS_report_part1.pdf (accessed on 03 Aug 2017).

27. Prendergast AJ, Humphrey JH. The stunting syndrome in developing countries. Paediatr Int Child Health 2014;34:250-65.

28. Danaei G, Andrews KG, Sudfeld CR, et al. Risk factors for childhood stunting in 137 developing countries: a comparative risk assessment analysis at global, regional, and country levels. PLoS Med 2016;13:e1002164.

29. Christian P, Lee SE, Donahue Angel M, et al. Risk of childhood undernutrition related to small-for-gestational age and preterm birth in low- and middle-income countries. Int J Epidemiol 2013;42:1340-55.

30. Sreeramareddy CT, Sathyanarayana TN, Kumar HN. Utilization of health care services for childhood morbidity and associated factors in India: a national cross-sectional household survey. PLoS One 2012; 7:e51904

31. Saksena $\mathrm{P}, \mathrm{Ke} X$, Elovainio $\mathrm{R}$, et al. Health services utilization and out-of-pocket expenditure at public and private facilities in lowincome countries. World Health Report (2010) Background Paper, No $20 \mathrm{http}: / /$ www.who.int/healthsystems/topics/financing/healthreport/ 20public-private.pdf (accessed on 08 Aug 2017).

32. National Health Mission. Ministry of Health and Family Welfare, Government of India. http://nhm.gov.in/communitisation/asha/aboutasha.html 